\title{
Aerobic Fitness Linked to Cortical Brain Development in Adolescent Males: Preliminary Findings Suggest a Possible Role of BDNF Genotype
}

\author{
Megan M. Herting ${ }^{1 *}$, Madison F. Keenan ${ }^{1}$ and Bonnie J. Nage/ ${ }^{2}$ \\ ${ }^{1}$ Department of Pediatrics, Children's Hospital Los Angeles, Los Angeles, CA, USA, ${ }^{2}$ Department of Behavioral \\ Neuroscience, Oregon Health \& Science University, Portland, OR, USA
}

Aerobic exercise has been shown to impact brain structure and cognition in children and adults. Exercise-induced activation of a growth protein known as brain derived neurotrophic factor (BDNF) is thought to contribute to such relationships. To date, however, no study has examined how aerobic fitness relates to cortical brain structure during development and if BDNF genotype moderates these relationships. Using structural magnetic resonance imaging (MRI) and FreeSurfer, the current study examined how aerobic fitness relates to volume, thickness, and surface area in 34 male adolescents, 15 to 18 years old. Moreover, we examined if the val66met BDNF genotype moderated these relationships. We hypothesized that aerobic fitness would relate to greater thickness and volumes in frontal, parietal, and motor regions, and that these relationships would be less robust in individuals carrying a Met allele, since this genotype leads to lower BDNF expression. We found that aerobic fitness positively related to right rostral middle frontal cortical volume in all adolescents. However, results also showed BDNF genotype moderated the relationship between aerobic fitness and bilateral medial

Edited by: Tetsuo Kida, National Institute for Physiological Sciences, Japan

Reviewed by: Arun Bokde, Trinity College Dublin, Ireland Keita Kamijo, Waseda University, Japan

*Correspondence: Megan M. Herting herting@usc.edu

Received: 05 April 2016 Accepted: 13 June 2016 Published: 30 June 2016

Citation:

Herting MM, Keenan MF and Nagel BJ (2016) Aerobic Fitness Linked to Cortical Brain Development in Adolescent Males: Preliminary Findings Suggest a Possible Role of BDNF Genotype.

Front. Hum. Neurosci. 10:327. doi: 10.3389/fnhum.2016.00327 precuneus surface area, with a positive relationship seen in individuals with the Val/ $\mathrm{Nal}$ allele, but no relationship detected in those adolescents carrying a Met allele. Lastly, using self-reported levels of aerobic activity, we found that higher-fit adolescents showed larger right medial pericalcarine, right cuneus and left precuneus surface areas as compared to their low-fit peers. Our findings suggest that aerobic fitness is linked to cortical brain development in male adolescents, and that more research is warranted to determine how an individual's genes may influence these relationships.

Keywords: exercise, BDNF, genotype, neuroimaging, adolescence, cortical volume

\section{INTRODUCTION}

Adolescence is a time period of significant neurodevelopment. Using structural magnetic resonance imaging (MRI), cortical volume has been shown to follow an inverted U-shaped pattern over development (Raznahan et al., 2011), with increases seen across childhood, peaking around early adolescence, and then decreasing before stablizing in adulthood (Giedd et al., 1999; Giedd, 2004). Within this measurement of cortical volume, two different aspects of the cortical sheet are also reflected: cortical thickness and surface area (Dale et al., 1999; Winkler et al., 2010, 2012). Cortical thickness is a measurement of the cortical ribbon, as defined as the distance between white matter and pial surfaces at each voxel; whereas surface 
area is defined as the area of the exposed cortical pial surface and hidden area of cortex within the sulci (Dale, 1999; Fischl et al., 2002, 2004). While related, cortical volume, thickness, and surface area are unique metrics showing distinct cellular, biological, and evolutionary relationships (Raznahan et al., 2011). The dynamic changes in cortical morphology across adolescence highlight the extraordinary plasticity of the brain during this period of development.

Given that the brain is still undergoing remodeling into the third decade of life, the developing adolescent brain is thought to be especially sensitive to environmental factors (Masten, 2004; Marco et al., 2011). In this regard, aerobic exercise is one environmental factor that may influence the developing adolescent brain, as it has been previously linked to brain and behavior improvements. Both cross-sectional and intervention studies have found aerobic exercise and fitness to relate to better performance on cognitive tasks in children, adolescents, and adults. For example, aerobic fitness has been associated with better learning and memory in children (Chaddock et al., 2010a, 2011), adolescents (Herting and Nagel, 2012), and the elderly (Erickson et al., 2011). Moreover, higher-fit children show better performance on tasks of executive functions, such as attention, compared to low-fit children (Chaddock et al., 2011, 2012a; Voss et al., 2011). Similar results have also been reported in older adults (Erickson and Kramer, 2009; Voss et al., 2012). These behavioral findings are mirrored by associations between aerobic fitness and brain volume. For example, better memory parallels positive correlations between aerobic fitness and larger hippocampus sizes across the lifespan (children (Chaddock et al., 2010a); adolescents (Herting and Nagel, 2012); and older adults (Erickson et al., 2011)). Furthermore, larger caudate volumes in children (Chaddock et al., 2010b) and older adults (Verstynen et al., 2012) have been shown to relate to aerobic exercise-related performance in executive functioning. However, relatively less research has examined how aerobic fitness relates to cortical gray matter brain volume across the lifespan. Using voxel-based morphometry, a 6-month aerobic exercise intervention study in older adults (ages 60-79 years) found increases in gray matter tissue density following intervention in the frontal, parietal, and temporal lobes compared to a non-aerobic control group (Colcombe et al., 2006). However, the same study showed that aerobic exercise did not predict increases in gray matter in a young adult sample (ages 18-30 years; Colcombe et al., 2006). Furthermore, despite differences in subcortical volumes, high and low-fit children were found to have similar total gray matter volumes (Chaddock et al., 2010b). To our knowledge, no study to date has examined how aerobic fitness relates to region specific differences in cortical gray matter volume, cortical thickness, or cortical surface area. Moreover, the current discrepancies in the brainexercise relationships across different samples could be due to differences in the limited quantification variables used to assess cortical structure (total gray matter volume, voxel-based morphometry). Thus, a more thorough assessment of how aerobic fitness relates to gray matter volume is warranted. Specifically, given the dynamic cortical changes that occur across adolescence, the unique and important relationship between aerobic fitness and cortical structure during this time deserves further investigation.

In addition to examining the influence of environmental factors (i.e., aerobic exercise), it is widely believed that complex genetic and environmental interactions exist to determine an individual's cortical neurodevelopment. Brainderived neurotrophic factor (BDNF), which plays a role in synaptic plasticity and cell growth and survival throughout the cortex, is thought to be vital in terms of exercise's influence on brain structure (for review see Cotman et al., 2007; van Praag, 2008, 2009). A three to four-fold increase is seen in BDNF following exercise (Neeper et al., 1995; Cotman and Berchtold, 2002), which continues after several weeks of exercise (RussoNeustadt et al., 1999). BDNF has also been shown to mediate the effect of exercise on brain and cognition in animals (Vaynman et al., 2004; Llorens-Martin et al., 2008). Individual differences in the BDNF gene, however, may also influence how exercise affects brain and behavior. The secretion and intracellular trafficking of BDNF is altered by a common functional single nucleotide polymorphism (SNP) within the BDNF gene, known as the val66met (Egan et al., 2003). Specifically, an amino acid substitution of the Valine (Val) to Methionine (Met) can occur at codon 66 of the prodomain of the BDNF gene. The Met substitution has been shown to lead to decreases in activitydependent secretion of BDNF as compared to the Val allele (Egan et al., 2003). The val66met genotype has been associated with regional cortical surface, thickness, and volume in adults (Pezawas et al., 2004; Wang et al., 2014); although, negative findings have been noted (Jessen et al., 2009; Koolschijn et al., 2010). One study recently showed that the benefits of exercise on cognition are moderated by BDNF allele status. Specifically, a four week exercise intervention resulted in improvements in cognition on an object recognition memory task in $\mathrm{Val} / \mathrm{Val}$ carriers, but not in those individuals with the Met substitution (Hopkins et al., 2012). Therefore, it is possible that the influence of aerobic fitness on cortical development may be further influenced by an individual's BDNF genotype.

The goals of the current study were to examine the association between aerobic fitness and cortical gray matter morphometrics in adolescents, including gray matter volume, surface area, and thickness. Given previous research showing aerobic exercise leads to better cognition and greater gray matter density in regions subserving cognitive function (Colcombe et al., 2006), we hypothesized that aerobic fitness would relate to greater thickness and volumes in frontal and parietal regions. Furthermore, we hypothesized that the relationships between aerobic fitness and cortical structure would be reduced in individuals with the Met substitution (Val/Met and Met/Met) as compared to those with a $\mathrm{Val} / \mathrm{Val}$ BDNF genotype.

\section{MATERIALS AND METHODS}

\section{Participants}

Thirty-four eligible male youths, ages 15-18, participated in the study as part of a more comprehensive neuroimaging 
study on exercise and the adolescent brain, including diffusion tensor imaging (Herting et al., 2014), hippocampal structure and function (Herting and Nagel, 2012) and functional magnetic resonance imaging (fMRI) verbal memory encoding (Herting and Nagel, 2013). All procedures of the current project were approved from Oregon Health \& Science University's Institutional Review Board and conducted in accordance with the Declaration of Helsinki. The study was adversitised through fliers, advertisements, and mailers circulated throughout the community. Participants and one of their parents underwent comprehensive structured interviews via telephone to determine eligibility after obtaining written consent and assent from all youths and at least one biological parent.

As previously reported, participants also had to meet either high or low-fit criteria via self-report on a modified version of the Youth Adolescent Activity Questionnaire (Wolf et al., 1994; Rifas-Shiman et al., 2001; for full details see Herting and Nagel (2013). Briefly, high-fit youth were defined as those participating in an average of $\geq 10 \mathrm{~h}$ per week of regular, organized aerobic physical activity, purposely performed to allow for improvement or maintenance of aerobic fitness across one or more seasons, within the past year. Low-fit youth were defined as those individuals that had participated in $\leq 1.5 \mathrm{~h}$ of aerobic physical activity per week over the past year. High-fit youth were asked to participate in the study during the season in which they were most physically active based on their YAAQ self-report. These criteria were set forth, as significant increases in aerobic fitness have been seen in adolescents who participated in $\geq 10 \mathrm{~h}$ of aerobic exercise per week (Brown et al., 1972; Weber et al., 1976; Lussier and Buskirk, 1977), and relatively extreme categorizations ( $\geq 10$ vs. $\leq 1.5 \mathrm{~h}$ per week) maximize the likelihood of detecting group differences.

Particpants were excluded if they had significant substance abuse ( $>10$ lifetime alcoholic drinks or 2 drinks/occasion, $>5$ uses of marijuana, any other drug use, or $>4$ cigarettes per day) [Brief Lifetime version of the Customary Drinking and Drug Use Record (Brown et al., 1998)]; a currently diagnosed DSM-IV psychiatric disorder [Diagnostic Interview Schedule for Children Predictive Scales (DISC-PS-4.32b; Lucas et al., 2001; Hoven et al., 2005)]; reported history of psychotic disorders in biological parents [Family History Assessment Module (FHAM; Rice et al., 1995)]; major medical condition or significant head trauma [Structured Clinical Interview (SCI; Brown et al., 1994)]; left-handedness [Edinburgh Handedness Inventory (Oldfield, 1971)], or irremovable metal. The current study was limited to recruitment of male adolescent participants. There are many inherent differences due to sex in brain structure [thickness, surface area, and volume] (Sowell et al., 2007; Lenroot and Giedd, 2010; Bramen et al., 2011, 2012) and aerobic capacity and physical fitness (Ekelund et al., 2001). As a consequence of these sex-specific disparaties, we chose to address the relationship of aerobic capacity and gray matter thickness, surface area, and volume in males only, thereby reducing variability within the study population for this preliminary work.

\section{Demographic Information and Potential Theoretical Confounds}

During the structured telephone interviews, information on age, ethnicity, and grade point average (GPA) was gathered. In order to account for non-exercise related factors that are also shown to influence cortical maturation, we assessed additional lifestyle factors. The Hollingshead Index of Social Position (ISP) was administered to parents to asses socioeconomic status (SES) based on each parents' occupation and educational attainment (Hollingshead, 1975). Each participant also provided self-report of their pubertal status [Pubertal Development Scale (PDS; Petersen et al., 1988)], and personal lifestyle habits involving nutrition, safety, relaxation, health promotion, and substance use [Revised Personal Lifestyle Questionnaire (PLQ; Mahon et al., 2003)]. These factors were assessed as SES (Noble et al., 2015), pubertal hormones (Herting et al., 2015), and a number of lifestyle factors (e.g., substance use) have been shown to relate to cortical volumes during adolescence (Jacobus et al., 2014, 2015; Squeglia et al., 2014, 2015).

\section{Procedure}

Over a 15-day time window, youths completed: (1) an aerobic fitness and physical activity assessment; (2) a blood-draw to determine BDNF genotyping; and (3) a MRI scanning session at Oregon Health \& Science University (OHSU).

\section{Aerobic Capacity Testing}

A computerized indirect calorimetry system (VMax Series, V6200 Autobox, Sensormedics, VIASYS Healthcare) assessed aerobic fitness of each participant by determining peak oxygen uptake rates $\left(\mathrm{VO}_{2}\right.$ peaks $)$ during exercise on a Bruce Protocol (Bruce et al., 1973). $\mathrm{VO}_{2}$ peak is considered the most valid objective measurement of aerobic physical fitness. The peak signifies the highest rate of oxygen transportation and utilization in the body during incremental exersize (Armstrong and Welsman, 2007). Participants ran on a motor-driven treadmill starting at $1.7 \mathrm{mph}$ with a $10 \%$ incline, with the speed and incline increasing every $3 \mathrm{~min}$, while participant heart rate was continuously measured. Additionally, every $2 \mathrm{~min}$, self-perceived measures of exertion were assessed on a scale of 0 (very easy) to 10 (very hard) until the particant reported exhaustion. Validity of $\mathrm{VO}_{2}$ peaks was required for consideration and determined by meeting at least one of the physiological criteria determining maximal effort outlined by Armstrong and van Mechelen (2008): (1) a plateau in oxygen consumption signifying that oxygen consumption remained at a steady state despite an increase in workload; (2) heart rate reached $\geq 200$ beats/min; (3) the respiratory exchange ratio $\geq 1.0$; and/or the subjective criteria of reporting a 10 on the perceived exertion scale. Just before aerobic testing participants' lean body mass (LBM) was determined using a biolectrical impedence test with a Body Composition Analyzer, Model 310e (Biodynamics Corp, Seattle, WA, USA). The independent measure of aerobic fitness was expressed as peak oxygen consumption in $\mathrm{mL} / \mathrm{kg} \mathrm{LBM} / \mathrm{min}$, as it allows for body fat to be minimized as a confounding variable in expressing fitness as it relates to metabolism in youths (Dencker et al., 2010). 


\section{BDNF Genotyping}

Blood was obtained via venapuncture by a trained phlebotomist at Oregon Clinical and Translational Research Center (OCTRI) at OHSU. Specimens were stored and genotyping was performed by the OCTRI core laboratory. Specifically, genomic DNA was extracted from whole blood using the Puregene system (Qiagen, Valencia, California, USA). The Val66Met SNP in the BDNF gene was genotyped by polymerase chain reaction (PCR) using primer sequences $5^{\prime}$-CAAACATCCGAGGACAAGGT$3^{\prime}$ and 5'-CCTCATGGACATGTTTGCAG-3' and ABI Amplitaq Gold 360 PCR kits (Applied Biosystems, Foster City, California, CA, USA). Following PCR the derived DNA product samples were sequenced using ABI BigDye v3.1 DNA sequencing kits following the manufacturer's procedures and analyzed on an ABI PRISM Genetic Analyzer $3130 \times$ L.

The frequency of the BDNF val66met allele in this male and predominantly caucasian group of adolescents was was $62.5 \%$ $\mathrm{Val} / \mathrm{Val}, 31 \% \mathrm{Met} / \mathrm{Val}$, and $6.3 \% \mathrm{Met} / \mathrm{Met}$, which is similar to frequencies observed in a large sample of Caucasian men (Pivac et al., 2009). The frequency of the val66met allele also did not signifcantly differ between high and low-fit participants $\left(X^{2}=2.2, p=0.33\right)$. However, given the few participants homozygous for the Met allele and previous findings that at least one Met-allele has been linked to brain structure (Pezawas et al., 2004) and cognition (Hopkins et al., 2012), participants in the current study with at least one Met allele were combined into a single "Met allele carriers" group.

\section{MRI Scanning Session}

All images were acquired at OHSU's Advanced Imaging Research Center on a 3.0 Tesla Siemens Magnetom Tim Trio system (Siemens Medical Solutions, Erlangen, Germany) with a 12-channel head coil. Whole-brain T1 weighted MPRAGE scanning sequence was collected in the sagittal plane (Inversion Time $(\mathrm{TI})=900 \mathrm{~ms}$, Flip Angle $=10$ degrees, Echo Time $(\mathrm{TE})=3.58 \mathrm{~ms}$, Repetition Time $(\mathrm{TR})=2300 \mathrm{~ms}$, acquisition matrix $=256 \times 240,160$ slices, resolution $=1 \times 1 \times 1.1 \mathrm{~mm}$ ).

\section{Image Processing and Statistical Analyses}

Images were analyzed with Freesurfer v5.3, which has been validated against histological analysis (Rosas et al., 2002). Images were processed for skull stripping (Segonne et al., 2004), automated registration to Talairach space, segmentation of the subcortical regions (Fischl et al., 2002, 2004), segmentation

\section{TABLE 1 | Participant demographics.}

\begin{tabular}{|c|c|c|c|c|}
\hline Demographics & All & HF & LF & HF vs. LF \\
\hline N & 34 & 17 & 17 & \\
\hline Age & $15.9(0.9)$ & $16.6(0.8)$ & $16.2(0.8)$ & $t_{(31.9)}=1.36, p=0.18$ \\
\hline$I^{a}$ & $117.7(9.6)$ & $117.1(11.8)$ & $118.0(7.1)$ & $t_{(26.1)}=0.26, p=0.79$ \\
\hline $\mathrm{SES}^{b}$ & $22.4(10.8)$ & $18.3(6.0)$ & $26.5(12.9)^{*}$ & $t_{(22.6)}=2.39, p=0.03$ \\
\hline Median household income ${ }^{b}$ (Thousands) & 113 & 130 & $90^{¥}$ & \\
\hline \multicolumn{5}{|l|}{ BDNF } \\
\hline \multicolumn{5}{|l|}{ Genotype* $^{*}$} \\
\hline $\mathrm{Val} / \mathrm{Val}$ & $20(62.5 \%)$ & 9 & 11 & $x^{2}=2.2, p=0.33$ \\
\hline Met carriers & $12(37.5 \%)$ & 7 & 5 & \\
\hline \multicolumn{5}{|l|}{ Daytime activity levels and aerobic fitness } \\
\hline Aerobic activity (h/wk over past year) ${ }^{d}$ & $5.5(5.8)$ & $11.3(3.4)$ & $0.26(0.5)^{* *}$ & $t_{(16.7)}=12.61, p<0.001$ \\
\hline \multicolumn{5}{|l|}{ Lifestyle } \\
\hline Nutrition $^{f ¥}$ & $12.2(1.3)$ & $12.0(1.0)$ & $12.4(1.5)$ & $t_{(31)}=0.77, p=0.45$ \\
\hline Relaxation $^{f ¥}$ & $15.3(2.2)$ & $15.2(2.2)$ & $15.4(2.2)$ & $t_{(31)}=0.22, p=0.83$ \\
\hline Health promotion ${ }^{f} ¥$ & $13.3(1.9)$ & $13.7(1.3)$ & $13.0(2.3)$ & $U=117, z=0.70, p=0.51$ \\
\hline Safety $¥ ¥$ & $14.6(1.3)$ & $14.2(1.3)$ & $15.0(1.2)$ & $U=86.5, z=1.8, p=0.07$ \\
\hline Substance use $e^{f ¥}$ & $11.5(0.8)$ & $11.6(0.5)$ & $11.3(1.0)$ & $U=122, z=0.58, p=0.63$ \\
\hline \multicolumn{5}{|l|}{ Extracurricular activities } \\
\hline Frequency & $3.8(0.7)$ & $4(0)$ & $3.5(1.0)$ & $U=110.5, z=2.09, p=0.25$ \\
\hline Number & $2.62(1.3)$ & $2.9(1.3)$ & $2.3(1.3)$ & $U=109, z=1.28, p=0.23$ \\
\hline
\end{tabular}

Means and standard deviations unless otherwise noted. ${ }^{\sharp} n=16$ due to missing data; ${ }^{*} p<0.05 ;{ }^{* *} p<0.01 ; h /$ wk $=$ hours per week. ${ }^{a}$ Wechsler Abbreviated Scale of Intelligence. ${ }^{b}$ Hollingshead Index of Social Position; lower values reflect higher SES. ${ }^{c}$ Pubertal Development Scale. ${ }^{d}$ Youth Adolescent Activity Questionnaire. ${ }^{e}$ Body Mass Index. ${ }^{f}$ Personal Lifestyle Questionnaire. ${ }^{*} N=32$. 
of gray, white, and CSF tissue, and intensity normalization (Dale and Sereno, 1993; Dale et al., 1999; Fischl and Dale, 2000). The surfaces were inflated (Fischl et al., 1999a) and registered to a spherical atlas which matched cortical geometry across subjects by utilizing individual cortical folding patterns (Fischl et al., 1999b), the cerebral cortex was portioned into gyri and sulci (Fischl et al., 2004; Desikan et al., 2006), and a cortical surface map was created based on curvature and sulcal depth. Image analysis was based on an intensity and continuity distribution from the entire MRI volume in segmentation and deformation procedures to produce representations of cortical thickness (Fischl and Dale, 2000). During map creation spatial intensity gradients were also used for each tissue class rather than absolute signal intensity. Lastly, each participant's brain was registered onto the Freesurfer average space and smoothed with a $10 \mathrm{~mm}$ full width at half maximum (FWHM) kernel. Each step of preprocessing was checked manually by MFK who was blind to participant demographics (aerobic fitness condition, age, PDS). Intracranial volume (ICV) was extracted and examined between the groups and as a function of $\mathrm{VO}_{2}$ peak as a potential covariate for volume analyses.

All statistical analyses of demographic variables were carried out using R Software (R Development Core Team, 2008). Normality was verified on all variables, and transformations were used when appropriate. When data continued to violate normality, nonparametric tests were employed. Students $t$-tests and Mann Whitney $U$ tests were used to examine between group differences on demographic variables. Pearson correlations were also used to determine if these potential confounding variables related to aerobic fitness $\left(\mathrm{VO}_{2}\right.$ peak). After identifying covariate(s) using R, FreeSurfer's general linear model QDEC program $\left(\mathrm{QDEC}^{1}\right)$ was used to perform whole brain vertexbased analyses for the dependent variables of interest, including average cortical thickness, surface area, and volume. For volume, thickness and surface area, the influence of aerobic fitness (i.e., $\mathrm{VO}_{2}$ peak) was examined, while controlling for potential confounding variables. Given that ICV was neither significantly different between $\mathrm{HF}$ and $\mathrm{LF}$ groups nor related to $\mathrm{VO}_{2}$ peak ( $\left.p^{\prime} s>0.64\right)$, it was not included in the model for volume. To correct for multiple comparisons, Monte Carlo corrections were applied, and significance was determined at those regions with $p$-values $<0.05$ after correction. Only results that passed multiple corrections are reported below.

\section{RESULTS}

\section{Participant Characteristics}

Participant characteristics can be found in Table 1. One participant's parent (low-fit) chose not to disclose total household income, one subject (high-fit) did not complete the PLQ, and two subjects (one low-fit, one high-fit) did not consent for storing blood to assess DNA; resulting in pairwise missing data for these measures. Significant group

\footnotetext{
${ }^{1}$ http://surfer.nmr.mgh.harvard.edu
}

TABLE 2 | Cortical structures showing: (a) group differences (high or low fitness); or (b) a relationship with aerobic fitness $\left(\mathrm{VO}_{2}\right.$ peak).

\begin{tabular}{|c|c|c|c|c|c|c|c|}
\hline & Region & $x$ & $Y$ & $z$ & $\begin{array}{c}\text { Size } \\
\left(\mathrm{mm}^{2}\right)\end{array}$ & $T$ & $\begin{array}{c}\text { Cohen's } \\
\text { d }\end{array}$ \\
\hline \multicolumn{8}{|c|}{ (a) Group differences } \\
\hline \multicolumn{8}{|c|}{ Surface area } \\
\hline Left & Precuneus & -12.0 & -67.1 & 34.7 & 3551.89 & 4.00 & 1.51 \\
\hline Right & Pericalcarine & 14.3 & -77.4 & 4.8 & 3281.16 & 4.00 & 1.51 \\
\hline \multicolumn{8}{|c|}{ (b) $\mathrm{VO}_{2}$ peak } \\
\hline & Rostral & & & & & & \\
\hline Left & $\begin{array}{l}\text { Middle } \\
\text { Frontal }\end{array}$ & -37.3 & 23.6 & 24.8 & 1083.62 & 2.14 & 0.77 \\
\hline
\end{tabular}

differences were seen in SES and PDS (Table 1). Pearson correlations were also used to determine if these potential confounding variables related to aerobic fitness $\left(\mathrm{VO}_{2}\right.$ peak). No relationship was detected between SES and $\mathrm{VO}_{2}$ peak, but PDS was shown to be negatively correlated with $\mathrm{VO}_{2}$ peak $(r=-0.37$, $\left.t_{(32)}=2.25, p=0.03\right)$. Thus, PDS and SES were included as covariates during between-group statistical testing, while PDS was included as a covariate when examining relationships between brain and the continuous variable of aerobic fitness $\left(\mathrm{VO}_{2}\right.$ peak).

\section{Cortical Structure}

\section{Group Differences}

Higher-fit adolescents showed larger right medial pericalcarine and cuneus and left precuneus surface areas as compared to lowfit adolescents (Table 2; Figure 1).

Correlations with aerobic fitness: a significant positive relationship was seen between $\mathrm{VO}_{2}$ peak and left rostral middle frontal cortical volume (Table 2; Figure 2). A significant $\mathrm{VO}_{2}$ peak and BDNF genotype interaction was found in bilateral lingual gyrus surface area (Table 3; Figure 3). Specifically, a significant positive relationship was seen between $\mathrm{VO}_{2}$ peak and surface area in those with the $\mathrm{Val} / \mathrm{Val}$ genotype (right hemisphere: $r=0.54, t_{(18)}=2.71, p=0.01$; left hemisphere:

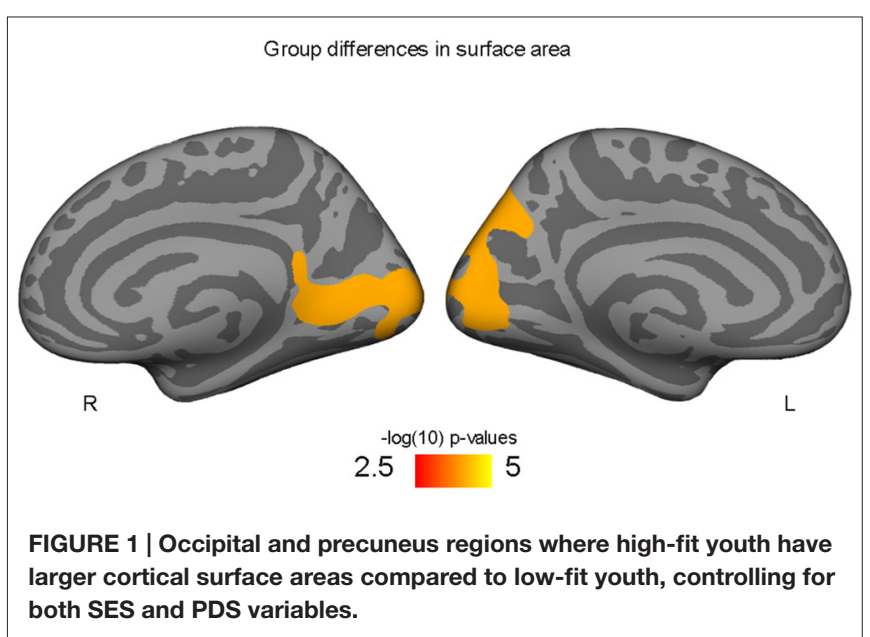




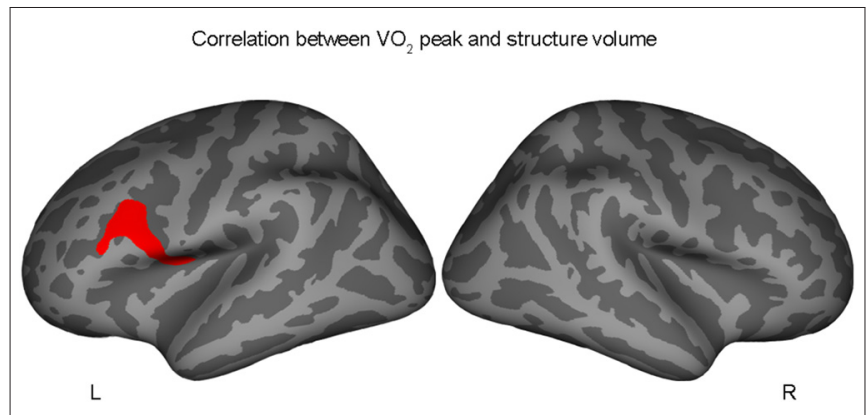

$2.5 \stackrel{-\log (10) \text { p-values }}{5}$

FIGURE 2 | Positive correlation between left rostral middle frontal volume and aerobic fitness $\left(\mathrm{VO}_{2}\right.$ peak), controlling for PDS variable.

$\left.r=0.50, t_{(18)}=2.48, p=0.02\right)$, whereas this relationship was not significant between $\mathrm{VO}_{2}$ peak and lingual gyrus surface area in Met allele carriers (right hemisphere: $r=-0.37, t_{(10)}=1.23$, $p=0.24$; left hemisphere: $\left.r=-0.44, t_{(10)}=1.57, p=0.15\right)$.

\section{DISCUSSION}

These findings show for the first time that aerobic fitness relates to cortical surface area and volume in adolescent male youth. Congruent with our a priori hypothesis that aerobic fitness would relate to larger cortical morphometrics in frontal and parietal regions, we found that greater aerobic fitness $\left(\mathrm{VO}_{2}\right.$ peak) predicted larger left middle prefrontal cortex volumes. In addition to our hypothesized prefrontal and parietal findings, we also found higher-fit adolescents had larger left precuneus and right occipital surface areas compared to their low-fit peers. Given that BDNF is thought to be responsible for exercise-related neuroplasticity, we also hypothesized that individual differences in the functional SNP within the BDNF gene may moderate how aerobic exercise related to cortical brain structure in this sample of male adolescents. Indeed, we found preliminary evidence that aerobic fitness predicted larger lingual gyrus surface area for those with the $\mathrm{Val} / \mathrm{Val}$ BDNF genotype, but a positive relationship was not seen in Met allele carriers.

After a peak in volume and surface area during late childhood and early adolescence, cortical maturation includes a reduction in gray matter volume and a contraction (or decrease) of the surface area across the latter period of adolescence (Giedd et al., 1999; Giedd, 2004). The developmental trajectory, however, varies greatly by brain region, with sensory and motor regions

TABLE 3 | Interaction between BDNF genotype and the correlation between structural surface area and $\mathrm{VO}_{2}$ peak.

\begin{tabular}{lllllll}
\hline Region & $X$ & $Y$ & $Z$ & $\begin{array}{c}\text { Size } \\
\left(\mathrm{mm}^{2}\right)\end{array}$ & $T$ & $\begin{array}{c}\text { Cohen's } \\
d\end{array}$ \\
\hline
\end{tabular}

\section{$\mathbf{V O}_{2}$ peak}

Surface area

$\begin{array}{llllllll}\text { Left } & \text { Lingual gyrus } & -21.4 & -61.3 & 8.9 & 2300.80 & -3.10 & -1.22\end{array}$

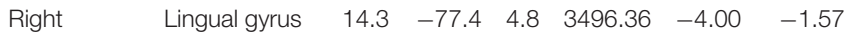

peaking earlier as compared to prefrontal and parietal cortices that peak later in adolescence (Sowell et al., 2004). While the exact mechanisms underlying changes in cortical volume and surface area during adolescence remains to be determined, it is thought the inverted- $U$ pattern reflects a proliferation of synapses followed by a pruning period (Lenroot and Giedd, 2006). Based on the known associations between aerobic fitness and executive function, we hypothesized that aerobic fitness may especially relate to larger cortical volumes, thickness, and surface area within the frontal and parietal lobes, since these regions are last to undergo maturation during this critical period of neuroplasticity. Along these lines, a positive association was found between aerobic fitness and frontal and parietal cortices in the current sample of adolescent males. These frontal and parietal findings are in agreement with previous studies. One study found that after completing a 6-month exercise intervention which required three 1 -h exercise training sessions per week, elderly individuals (60-79 years) showed an increase in $\mathrm{VO}_{2}$ peak, as well as increases in lateral prefrontal and parietal cortical volumes (Colcombe et al., 2006). In addition, the anatomical locations of our findings are in line with the larger body of literature suggesting aerobic fitness may benefit cognition (Erickson and Kramer, 2009; Voss et al., 2011; Chaddock et al., 2012b). The rostral middle frontal cortex (also known as the dorsal lateral prefrontal cortex) and the precuneus are brain regions known to be important for executive functions, including attention and working memory (Wager and Smith, 2003; Funahashi, 2006; Parks and Madden, 2013). However, despite these similarities, it is interesting to note that other studies have found no significant differences in gray matter volumes between high vs. low-fit pre-pubertal children (Chaddock et al., 2010b). Similarly, no changes in gray matter volumes were found in young adults (18-30 years) following the aforementioned 6-month exercise intervention program that lead to volumetric changes in the elderly sample (Colcombe et al., 2006). Although the research between aerobic fitness and cortical size is limited, a discrepancy in results across samples could be due to the use of different methods. For example, the current study examined cortical volume and surface area measured by Freesurfer, as compared to the elderly and adult studies, which used voxel based morphometry. In addition, the child study by Chaddock et al. (2010b) used Freesurfer to examine high and low-fit children, but results may have been confounded by the low-fit children having higher BMI (a variable on which our groups were not significantly different), as BMI and obesity have been shown to relate to brain volumes in other samples (Yokum et al., 2012; Alosco et al., 2014; Ou et al., 2015). Alternatively, it is also feasible that aerobic exercise may have varying effects on the brain as a function of age, with larger effects seen during dynamic remodeling or age-related decline, such as adolescence and aging, respectively.

Because sensorimotor regions are typically thought to mature earlier in adolescence, we did not expect to see group differences, as well as a significant fitness-by-genotype interaction, in brain regions important for visual processing, including the occipital cortex and lingual gyrus. However, in a more recent 


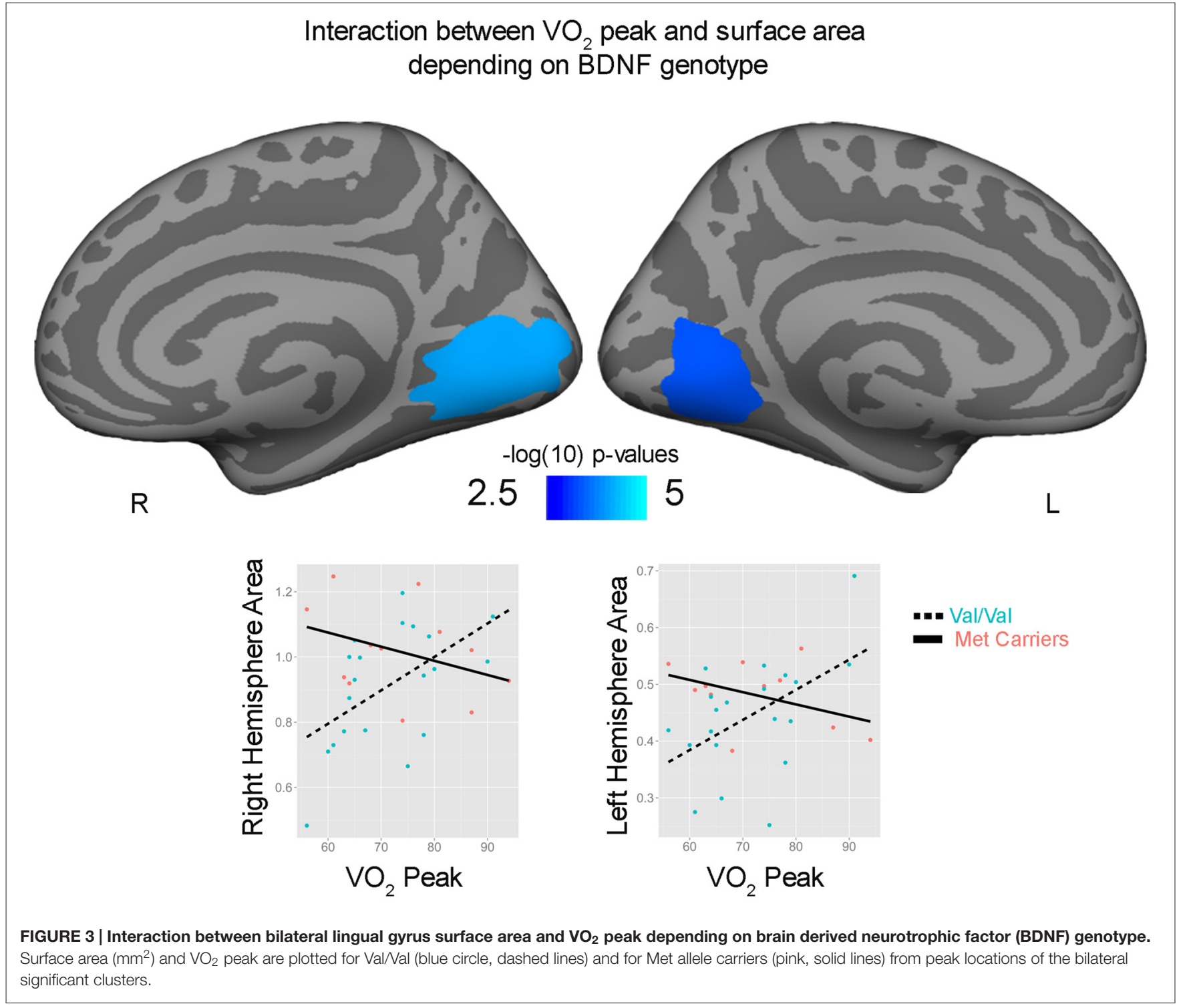

longitudinal MRI study, surface areas of occipital regions (including the precuneus and lingual gyrus) were found to peak between 11 and 20 years of age, suggesting these visual areas also remain dynamic as well across adolescence (Vijayakumar et al., 2016). Moreover, while the lingual gyrus is involved in vision, its role in brain function likely goes beyond basic sensory processing. Through its interactions with the prefrontal cortex, the lingual gyrus has been implicated in modulating selective visual attention (Hopfinger et al., 2000; Vuilleumier et al., 2005). Thus, vantage points, visual search, anticipation, and fast reaction times are visual properties that may be essential to sports and engaging in various types of aerobic exercise. One hypothesis could be that aerobic exercise is associated with occipital lobe structure due to both basic, as well as higher-order visual abilities required and/or affected by exercise participation. However, given the cross-sectional design of the current study, it remains to be determined if aerobic exercise leads to greater surface area and volumes in these regions across adolescence, or if cortical size in these regions may in fact predispose children to perform aerobic exercise and/or participate in sports. In addition, it remains to be elucidated if the larger volumes and surface areas seen in the current cross-sectional study are due to potential changes in developmental plasticity resulting from aerobic fitness, such as: (1) a larger peak in surface area or volume (e.g., "larger proliferation of synapsis") during early adolescence; (2) less of an age-related decrease in surface area or volume (e.g., "less pruning") from adolescence into adulthood, or both. Along these lines, animal studies support the idea that voluntary exercise may increase visual cortex gray matter volumes, as well as increase plasticity in the visual cortex. Sumiyoshi et al. (2014) found that wheel running in rodents from birth to adulthood resulted in prolonging plasticity in the visual cortex, as seen by an extension of the sensitive period of plasticity into adulthood that allowed for a shift in ocular dominance following monocular deprivation 
(Kalogeraki et al., 2014). While acute effects of exercise do not necessarily translate to long-term chronic effects, a few human adult studies also suggest that, at least acutely, aerobic exercise does in fact change occipital function as seen by functional MRI (Yagi et al., 1999; Li et al., 2014). Thus, longitudinal exercise intervention studies that follow the same individuals over time will be essential to determine if chronic exercise during childhood and adolescence may contribute to previously reported improvements in cognition and brain function through changes in developmental trajectories and prolonged neuroplasticity across development.

The current study also provides preliminary results on how associations between aerobic fitness and brain structure may vary based on an individual's BDNF genotype. It is important to note that the current study is limited by its small sample size, and only large effect sizes could be detected. As such, the interaction between BDNF genotype and aerobic fitness on bilateral lingual surface area suggests that future research examining the interactions between aerobic fitness and BDNF genotype in larger samples is warranted in order to assess small or medium effects of BDNF genotype that may have been undetectable in the current study. Despite the sample size limitation, these preliminary findings highlight that cortical development is likely a complex and dynamic process influenced by genes, environment, and their interactions (Lenroot et al., 2009). In fact, recent studies have shown that the relative influence of genes verus environment (and their interaction) on cortical development varies across brain region and with age (Lenroot et al., 2009). That is, motor and sensory regions that develop relatively earlier in development (Gogtay et al., 2004) show greater heritability early in childhood, whereas high-order prefrontal and parietal regions show increasing genetic effects later in adolescence (Lenroot et al., 2009). Beyond BDNF, other genes have also been found to influence the relationship between aerobic fitness and brain outcomes. For example, the apolipoprotein e (ApoE) genotype has been shown to moderate the influence of aerobic exercise on brain structure in elderly and aging samples (Honea et al., 2009). More recently, epigenetic mechanisms and microRNA have also been found to be responsive to exercise in brain cells in animals (Denham et al., 2014). Together, these findings suggest that an individual's genes, as well as the expression of those genes, may be especially important

\section{REFERENCES}

Alosco, M. L., Stanek, K. M., Galioto, R., Korgaonkar, M. S., Grieve, S. M., Brickman, A. M., et al. (2014). Body mass index and brain structure in healthy children and adolescents. Int. J. Neurosci. 124, 49-55. doi: 10.3109/00207454. 2013.817408

Armstrong, N., and Welsman, J. R. (2007). Aerobic fitness: what are we measuring? Med. Sport Sci. 50, 5-25. doi: 10.1159/000101073

Armstrong, N., and van Mechelen, W. (2008). Paediatric Exercise Science and Medicine. New York, NY: Oxford University Press Inc.

Bramen, J. E., Hranilovich, J. A., Dahl, R. E., Chen, J., Rosso, C., Forbes, E. E., et al. (2012). Sex matters during adolescence: testosterone-related cortical thickness maturation differs between boys and girls. PloS One 7:e33850. doi: 10 . 1371/journal.pone.0033850 factors in understanding how aerobic exercise may affect the brain. While complex, future studies aimed at clarifying the possible interactive effects of aerobic fitness, various genotypes, and gene expression on neurodevelopment will ultimately help us to determine when, how, and to what degree, aerobic exercise may influence the child and adolescent brain.

In summary, we show for the first time that aerobic fitness in late adolescent males relates to frontal, parietal, and occipital cortex structure. In addition, we provide preliminary findings that BDNF genetoype may moderate the relationship between aerobic fitness and cortical structure in adolescents. Further large-scaled longitudinal studies are needed to further elucidate how aerobic fitness may alter neurodevelopmental trajectories and to what degree an individual's genes may moderate the effect of aerobic exercise on the adolescent brain.

\section{AUTHOR CONTRIBUTIONS}

$\mathrm{MMH}$ and BJN were responsible for study conception, design, and data acquisition, whereas $\mathrm{MMH}$ and MFK conducted structural MRI preprocessing and data analyses. All authors (MMH, MFK, BJN) contributed to interpretation of the data, drafting and revision of the intellectual content, have given approval for publication, and are accountable for all aspects of the work.

\section{ACKNOWLEDGMENTS}

This research was supported by the National Institute of Alcohol Abuse and Addiction Grant (F31AA019866 to MMH; R01 AA017664 to BJN), the Dana Foundation (BJN), the National Institute of Neurological Disorders and Stroke (K08 NS052147 to BJN), the Oregon Clinical and Translational Research Institute, the OHSU Tartar Trust Research Fellowship (MMH), American Psychological Association Science Directorate's Dissertation Research Award (MMH), and ARCS Foundation, Inc. Portland Chapter (MMH). A special thanks to Madison Stroup, Khadiya Chinnarath, Jill Waldman, Stephanie Sasse, Jenny Peraza, and Kristen Seghete for their assistance in data collection and data entry. Thank you to Dr. Elliot for her help with aerobic fitness testing.

Bramen, J. E., Hranilovich, J. A., Dahl, R. E., Forbes, E. E., Chen, J., Toga, A. W., et al. (2011). Puberty influences medial temporal lobe and cortical gray matter maturation differently in boys than girls matched for sexual maturity. Cereb. Cortex 21, 636-646. doi: 10.1093/cercor/bhq137

Brown, C. H., Harrower, J. R., and Deeter, M. F. (1972). The effects of crosscountry running on pre-adolescent girls. Med. Sci. Sports 4, 1-5.

Brown, S. A., Myers, M. G., Lippke, L., Tapert, S. F., Stewart, D. G., and Vik, P. W. (1998). Psychometric evaluation of the Customary Drinking and Drug Use Record (CDDR): a measure of adolescent alcohol and drug involvement. J. Stud. Alcohol 59, 427-438. doi: 10.15288/jsa.1998. 59.427

Brown, S. A., Myers, M. G., Mott, M. A., and Vik, P. W. (1994). Correlates of success following treatment for adolescent substance abuse. Appl. Prev. Psychol. 3, 61-73. doi: 10.1016/s0962-1849(05)80139-8 
Bruce, R. A., Kusumi, F., and Hosmer, D. (1973). Maximal oxygen intake and nomographic assessment of functional aerobic impairment in cardiovascular disease. Am. Heart J. 85, 546-562. doi: 10.1016/0002-8703(73) 90502-4

Chaddock, L., Hillman, C. H., Buck, S. M., and Cohen, N. J. (2011). Aerobic fitness and executive control of relational memory in preadolescent children. Med. Sci. Sports Exerc. 43, 344-349. doi: 10.1249/MSS.0b013e3181e9af48

Chaddock, L., Erickson, K. I., Prakash, R. S., Voss, M. W., VanPatter, M., Pontifex, M. B., et al. (2012a). A functional MRI investigation of the association between childhood aerobic fitness and neurocognitive control. Biol. Psychol. 89, 260-268. doi: 10.1016/j.biopsycho.2011.10.017

Chaddock, L., Hillman, C. H., Pontifex, M. B., Johnson, C. R., Raine, L. B., and Kramer, A. F. (2012b). Childhood aerobic fitness predicts cognitive performance one year later. J. Sports Sci. 30, 421-430. doi: 10.1080/02640414. 2011.647706

Chaddock, L., Erickson, K. I., Prakash, R. S., Kim, J. S., Voss, M. W., Vanpatter, M., et al. (2010a). A neuroimaging investigation of the association between aerobic fitness, hippocampal volume and memory performance in preadolescent children. Brain Res. 1358, 172-183. doi: 10.1016/j.brainres.2010.08.049

Chaddock, L., Erickson, K. I., Prakash, R. S., VanPatter, M., Voss, M. W., Pontifex, M. B., et al. (2010b). Basal ganglia volume is associated with aerobic fitness in preadolescent children. Dev. Neurosci. 32, 249-256. doi: 10.1159/0003 16648

Colcombe, S. J., Erickson, K. I., Scalf, P. E., Kim, J. S., Prakash, R., McAuley, E., et al. (2006). Aerobic exercise training increases brain volume in aging humans. J. Gerontol. A Biol. Sci. Med. Sci. 61, 1166-1170. doi: 10.1093/gerona/61.11.1166

Cotman, C. W., and Berchtold, N. C. (2002). Exercise: a behavioral intervention to enhance brain health and plasticity. Trends Neurosci. 25, 295-301. doi: 10 . 1016/s0166-2236(02)02143-4

Cotman, C. W., Berchtold, N. C., and Christie, L. A. (2007). Exercise builds brain health: key roles of growth factor cascades and inflammation. Trends Neurosci. 30, 464-472. doi: 10.1016/j.tins.2007.06.011

Dale, A. M. (1999). Optimal experimental design for event-related fMRI. Hum. Brain Mapp. 8, 109-114. doi: 10.1002/(sici)1097-0193(1999)8:2/3<109::aidhbm7>3.0.co; $2-\mathrm{w}$

Dale, A. M., Fischl, B., and Sereno, M. I. (1999). Cortical surface-based Segmentation, analysis. I. and surface reconstruction. Neuroimage 9, 179-194. doi: 10.1006/nimg.1998.0395

Dale, A. M., and Sereno, M. I. (1993). Improved localizadon of cortical activity by combining EEG and MEG with MRI cortical surface reconstruction: a linear approach. J. Cogn. Neurosci. 5, 162-176. doi: 10.1162/jocn.1993.5.2.162

Dencker, M., Bugge, A., Hermansen, B., Froberg, K., and Andersen, L. B. (2010). Aerobic fitness in prepubertal children according to level of body fat. Acta Paediatr. 99, 1854-1860. doi: 10.1111/j.1651-2227.2010.01952.x

Denham, J., Marques, F. Z., O’Brien, B. J., and Charchar, F. J. (2014). Exercise: putting action into our epigenome. Sports Med. 44, 189-209. doi: 10. 1007/s40279-013-0114-1

Desikan, R. S., Ségonne, F., Fischl, B., Quinn, B. T., Dickerson, B. C., Blacker, D., et al. (2006). An automated labeling system for subdividing the human cerebral cortex on MRI scans into gyral based regions of interest. Neuroimage 31, 968-980. doi: 10.1016/j.neuroimage.2006.01.021

Egan, M. F., Kojima, M., Callicott, J. H., Goldberg, T. E., Kolachana, B. S., Bertolino, A., et al. (2003). The BDNF val66met polymorphism affects activitydependent secretion of BDNF and human memory and hippocampal function. Cell 112, 257-269. doi: 10.1016/s0092-8674(03)00035-7

Ekelund, U., Poortvliet, E., Nilsson, A., Yngve, A., Holmberg, A., and Sjostrom, M. (2001). Physical activity in relation to aerobic fitness and body fat in 14- to 15-year-old boys and girls. Eur. J. Appl. Physiol. 85, 195-201. doi: 10. $1007 /$ s004210100460

Erickson, K. I., and Kramer, A. F. (2009). Aerobic exercise effects on cognitive and neural plasticity in older adults. Br. J. Sports Med. 43, 22-24. doi: 10.1136/bjsm. 2008.052498

Erickson, K. I., Voss, M. W., Prakash, R. S., Basak, C., Szabo, A., Chaddock, L., et al. (2011). Exercise training increases size of hippocampus and improves memory. Proc. Natl. Acad. Sci. U S A 108, 3017-3022. doi: 10.1073/pnas.1015950108

Fischl, B., and Dale, A. M. (2000). Measuring the thickness of the human cerebral cortex from magnetic resonance images. Proc. Natl. Acad. Sci. U S A 97, 11050-11055. doi: 10.1073/pnas.200033797
Fischl, B., Salat, D. H., Busa, E., Albert, M., Dieterich, M., Haselgrove, C., et al. (2002). Whole brain segmentation: automated labeling of neuroanatomical structures in the human brain. Neuron 33, 341-355. doi: 10.1016/S08966273(02)00569-X

Fischl, B., Sereno, M. I., and Dale, A. M. (1999a). Cortical surface-based analysis. II: inflation, flattening and a surface-based coordinate system. Neuroimage 9, 195-207. doi: 10.1006/nimg.1998.0396

Fischl, B., Sereno, M. I., Tootell, R. B., and Dale, A. M. (1999b). High-resolution intersubject averaging and a coordinate system for the cortical surface. Hum. Brain Mapp. 8, 272-284. doi: 10.1002/(sici)1097-0193(1999)8:4<272::aidhbm10>3.0.co;2-4

Fischl, B., van der Kouwe, A., Destrieux, C., Halgren, E., Ségonne, F., Salat, D. H., et al. (2004). Automatically parcellating the human cerebral cortex. Cereb. Cortex 14, 11-22. doi: 10.1093/cercor/bhg087

Funahashi, S. (2006). Prefrontal cortex and working memory processes. Neuroscience 139, 251-261. doi: 10.1016/j.neuroscience.2005.07.003

Giedd, J. N. (2004). Structural magnetic resonance imaging of the adolescent brain. Ann. N Y Acad. Sci. 1021, 77-85. doi: 10.1196/annals.1308.009

Giedd, J. N., Blumenthal, J., Jeffries, N. O., Castellanos, F. X., Liu, H., Zijdenbos, A., et al. (1999). Brain development during childhood and adolescence: a longitudinal MRI study. Nat. Neurosci. 2, 861-863. doi: 10.1038/13158

Gogtay, N., Giedd, J. N., Lusk, L., Hayashi, K. M., Greenstein, D., Vaituzis, A. C., et al. (2004). Dynamic mapping of human cortical development during childhood through early adulthood. Proc. Natl. Acad. Sci. U S A 101, 8174-8179. doi: 10.1073/pnas.0402680101

Herting, M. M., Colby, J. B., Sowell, E. R., and Nagel, B. J. (2014). White matter connectivity and aerobic fitness in male adolescents. Dev. Cogn. Neurosci. 7, 65-75. doi: 10.1016/j.dcn.2013.11.003

Herting, M. M., Gautam, P., Spielberg, J. M., Dahl, R. E., and Sowell, E. R. (2015). A longitudinal study: changes in cortical thickness and surface area during pubertal maturation. PLoS One 10:e0119774. doi: 10.1371/journal.pone. 0119774

Herting, M. M., and Nagel, B. J. (2012). Aerobic fitness relates to learning on a virtual Morris Water Task and hippocampal volume in adolescents. Behav. Brain Res. 233, 517-525. doi: 10.1016/j.bbr.2012.05.012

Herting, M. M., and Nagel, B. J. (2013). Differences in brain activity during a verbal associative memory encoding task in high- and low-fit adolescents. J. Cogn Neurosci. 25, 595-612. doi: 10.1162/jocn_a_00344

Hollingshead, A. B. (1975). Four Factor Index of Social Status. New Haven, CT: Yale University.

Honea, R. A., Thomas, G. P., Harsha, A., Anderson, H. S., Donnelly, J. E., Brooks, W. M., et al. (2009). Cardiorespiratory fitness and preserved medial temporal lobe volume in Alzheimer's disease. Alzheimer Dis. Assoc. Disord. 23, 188-197. doi: 10.1097/WAD.0b013e31819cb8a2

Hopfinger, J. B., Buonocore, M. H., and Mangun, G. R. (2000). The neural mechanisms of top-down attentional control. Nat. Neurosci. 3, 284-291. doi: $10.1038 / 72999$

Hopkins, M. E., Davis, F. C., Vantieghem, M. R., Whalen, P. J., and Bucci, D. J. (2012). Differential effects of acute and regular physical exercise on cognition and affect. Neuroscience 215, 59-68. doi: 10.1016/j.neuroscience.2012. 04.056

Hoven, C. W., Duarte, C. S., Lucas, C. P., Wu, P., Mandell, D. J., Goodwin, R. D., et al. (2005). Psychopathology among New York city public school children 6 months after September 11. Arch. Gen. Psychiatry 62, 545-552. doi: 10. 1001/archpsyc.62.5.545

Jacobus, J., Squeglia, L. M., Meruelo, A. D., Castro, N., Brumback, T., Giedd, J. N., et al. (2015). Cortical thickness in adolescent marijuana and alcohol users: a three-year prospective study from adolescence to young adulthood. Dev. Cogn. Neurosci. 16, 101-109. doi: 10.1016/j.dcn.2015.04.006

Jacobus, J., Squeglia, L. M., Sorg, S. F., Nguyen-Louie, T. T., and Tapert, S. F. (2014). Cortical thickness and neurocognition in adolescent marijuana and alcohol users following 28 days of monitored abstinence. J. Stud. Alcohol Drugs 75, 729-743. doi: 10.15288/jsad.2014.75.729

Jessen, F., Schuhmacher, A., von Widdern, O., Guttenthaler, V., Hofels, S., Suliman, H., et al. (2009). No association of the Val66Met polymorphism of the brain-derived neurotrophic factor with hippocampal volume in major depression. Psychiat. Genet. 19, 99-101. doi: 10.1097/YPG.0b013e3283 2080ce 
Kalogeraki, E., Greifzu, F., Haack, F., and Löwel, S. (2014). Voluntary physical exercise promotes ocular dominance plasticity in adult mouse primary visual cortex. J. Neurosci. 34, 15476-15481. doi: 10.1523/JNEUROSCI.267814.2014

Koolschijn, P. C., van Haren, N. E., Bakker, S. C., Hoogendoorn, M. L., Hulshoff Pol, H. E., and Kahn, R. S. (2010). Effects of brain-derived neurotrophic factor Val66Met polymorphism on hippocampal volume change in schizophrenia. Hippocampus 20, 1010-1017. doi: 10.1002/hipo.20699

Lenroot, R. K., and Giedd, J. N. (2006). Brain development in children and adolescents: insights from anatomical magnetic resonance imaging. Neurosci. Biobehav. Rev. 30, 718-729. doi: 10.1016/j.neubiorev.2006.06.001

Lenroot, R. K., and Giedd, J. N. (2010). Sex differences in the adolescent brain. Brain Cogn. 72, 46-55. doi: 10.1016/j.bandc.2009.10.008

Lenroot, R. K., Schmitt, J. E., Ordaz, S. J., Wallace, G. L., Neale, M. C., Lerch, J. P., et al. (2009). Differences in genetic and environmental influences on the human cerebral cortex associated with development during childhood and adolescence. Hum. Brain Mapp. 30, 163-174. doi: 10.1002/ hbm.20494

Li, L., Men, W. W., Chang, Y. K., Fan, M. X., Ji, L., and Wei, G. X. (2014). Acute aerobic exercise increases cortical activity during working memory: a functional MRI study in female college students. PLoS One 9:e99222. doi: 10. 1371/journal.pone.0099222

Llorens-Martin, M., Torres-Aleman, I., and Trejo, J. L. (2008). Growth factors as mediators of exercise actions on the brain. Neuromolecular Med. 10, 99-107. doi: 10.1007/s12017-008-8026-1

Lucas, C. P., Zhang, H., Fisher, P. W., Shaffer, D., Regier, D. A., Narrow, W. E., et al. (2001). The DISC Predictive Scales (DPS): efficiently screening for diagnoses. J. Am. Acad. Child Adolesc. Psychiatry 40, 443-449. doi: 10. 1097/00004583-200104000-00013

Lussier, L., and Buskirk, E. R. (1977). Effects of an endurance training regimen on assessment of work capacity in prepubertal children. Ann. N Y Acad. Sci. 301, 734-747. doi: 10.1111/j.1749-6632.1977.tb38243.x

Mahon, N. E., Yarcheski, T. J., and Yarcheski, A. (2003). The revised personal lifestyle questionnaire for early adolescents. West J. Nurs. Res. 25, 533-547. doi: $10.1177 / 0193945903253000$

Marco, E. M., Macri, S., and Laviola, G. (2011). Critical age windows for neurodevelopmental psychiatric disorders: evidence from animal models. Neurotox. Res. 19, 286-307. doi: 10.1007/s12640-010-9205-z

Masten, A. S. (2004). Regulatory processes, risk and resilience in adolescent development. Ann. N Y Acad. Sci. 1021, 310-319. doi: 10.1196/annals. 1308.036

Neeper, S. A., Gómez-Pinilla, F., Choi, J., and Cotman, C. (1995). Exercise and brain neurotrophins. Nature 373:109. doi: 10.1038/373109a0

Noble, K. G., Houston, S. M., Brito, N. H., Bartsch, H., Kan, E., Kuperman, J. M., et al. (2015). Family income, parental education and brain structure in children and adolescents. Nat. Neurosci. 18, 773-778. doi: 10.1038/nn.3983

Oldfield, R. C. (1971). The assessment and analysis of handedness: the Edinburgh inventory. Neuropsychologia 9, 97-113. doi: 10.1016/0028-3932(71) 90067-4

Ou, X., Andres, A., Pivik, R. T., Cleves, M. A., and Badger, T. M. (2015). Brain gray and white matter differences in healthy normal weight and obese children. J. Magn. Reson. Imaging 42, 1205-1213. doi: 10.1002/jmri.24912

Parks, E. L., and Madden, D. J. (2013). Brain connectivity and visual attention. Brain Connect. 3, 317-338. doi: 10.1089/brain.2012.0139

Petersen, A., Crockett, L., Richards, M., and Boxer, A. (1988). A self-report measure of pubertal status: reliability, validity and initial norms. J. Youth Adolesc. 17, 117-133. doi: 10.1007/BF01537962

Pezawas, L., Verchinski, B. A., Mattay, V. S., Callicott, J. H., Kolachana, B. S., Straub, R. E., et al. (2004). The brain-derived neurotrophic factor val66met polymorphism and variation in human cortical morphology. J. Neurosci. 24, 10099-10102. doi: 10.1523/JNEUROSCI.2680-04.2004

Pivac, N., Kim, B., Nedić, G., Joo, Y. H., Kozarić-Kovacić, D., Hong, J. P., et al. (2009). Ethnic differences in brain-derived neurotrophic factor Val66Met polymorphism in Croatian and Korean healthy participants. Croat. Med. J. 50, 43-48. doi: $10.3325 / \mathrm{cmj} .2009 .50 .43$

Raznahan, A., Shaw, P., Lalonde, F., Stockman, M., Wallace, G. L., Greenstein, D., et al. (2011). How does your cortex grow? J. Neurosci. 31, 7174-7177. doi: 10. 1523/JNEUROSCI.0054-11.2011
R Development Core Team. (2008). R: A Language and Environment for Statistical Computing. Vienna, Austria: R.F.f.S. Computing.

Rice, J. P., Reich, T., Bucholz, K. K., Neuman, R. J., Fishman, R., Rochberg, N., et al. (1995). Comparison of direct interview and family history diagnoses of alcohol dependence. Alcohol. Clin. Exp. Res. 19, 1018-1023. doi: 10.1111/j.1530-0277. 1995.tb00983.x

Rifas-Shiman, S. L., Gillman, M. W., Field, A. E., Frazier, A. L., Berkey, C. S., Tomeo, C. A., et al. (2001). Comparing physical activity questionnaires for youth: seasonal vs annual format. Am. J. Prev. Med. 20, 282-285. doi: 10.1016/ s0749-3797(01)00296-3

Rosas, H. D., Liu, A. K., Hersch, S., Glessner, M., Ferrante, R. J., Salat, D. H., et al. (2002). Regional and progressive thinning of the cortical ribbon in Huntington's disease. Neurology 58, 695-701. doi: 10.1212/WNL. 58.5.695

Russo-Neustadt, A., Beard, R. C., and Cotman, C. W. (1999). Exercise, antidepressant medications and enhanced brain derived neurotrophic factor expression. Neuropsychopharmacology 21, 679-682. doi: 10.1016/s0893-133x (99)00059-7

Segonne, F., Dale, A. M., Busa, E., Glessner, M., Salat, D., Hahn, H. K., et al. (2004). A hybrid approach to the skull stripping problem in MRI. Neuroimage 22, 1060-1075. doi: 10.1016/s1053-8119(04)00188-0

Sowell, E. R., Peterson, B. S., Kan, E., Woods, R. P., Yoshii, J., Bansal, R., et al. (2007). Sex differences in cortical thickness mapped in 176 healthy individuals between 7 and 87 years of age. Cereb. Cortex 17, 1550-1560. doi: 10 . 1093/cercor/bhl066

Sowell, E. R., Thompson, P. M., Leonard, C. M., Welcome, S. E., Kan, E., and Toga, A. W. (2004). Longitudinal mapping of cortical thickness and brain growth in normal children. J. Neurosci. 24, 8223-8231. doi: 10.1523/JNEUROSCI.179804.2004

Squeglia, L. M., Rinker, D. A., Bartsch, H., Castro, N., Chung, Y., Dale, A. M., et al. (2014). Brain volume reductions in adolescent heavy drinkers. Dev. Cogn. Neurosci. 9, 117-125. doi: 10.1016/j.den.2014.02.005

Squeglia, L. M., Tapert, S. F., Sullivan, E. V., Jacobus, J., Meloy, M. J., Rohlfing, T., et al. (2015). Brain development in heavy-drinking adolescents. Am J Psychiatry 172, 531-542. doi: 10.1176/appi.ajp.2015.14101249

Sumiyoshi, A., Taki, Y., Nonaka, H., Takeuchi, H., and Kawashima, R. (2014), Regional gray matter volume increases following 7 days of voluntary wheel running exercise: a longitudinal VBM study in rats. Neuroimage 98, 82-90. doi: 10.1016/j.neuroimage.2014.04.075

van Praag, H. (2008). Neurogenesis and exercise: past and future directions. Neuromolecular Med. 10, 128-140. doi: 10.1007/s12017-0088028-z

van Praag, H. (2009). Exercise and the brain: something to chew on. Trends Neurosci. 32, 283-290. doi: 10.1016/j.tins.2008.12.007

Vaynman, S., Ying, Z., and Gomez-Pinilla, F. (2004). Hippocampal BDNF mediates the efficacy of exercise on synaptic plasticity and cognition. Eur. J. Neurosci. 20, 2580-2590. doi: 10.1111/j.1460-9568.2004. 03720.x

Verstynen, T. D., Lynch, B., Miller, D. L., Voss, M. W., Prakash, R. S., Chaddock, L., et al. (2012). Caudate nucleus volume mediates the link between cardiorespiratory fitness and cognitive flexibility in older adults. J. Aging Res. 2012:939285. doi: 10.1155/2012/939285

Vijayakumar, N., Allen, N. B., Youssef, G., Dennison, M., Yücel, M., Simmons, J. G., et al. (2016). Brain development during adolescence: a mixed-longitudinal investigation of cortical thickness, surface area and volume. Hum. Brain Mapp. 37, 2027-2038. doi: 10.1002/hbm.23154

Voss, M. W., Chaddock, L., Kim, J. S., Vanpatter, M., Pontifex, M. B., Raine, L. B., et al. (2011). Aerobic fitness is associated with greater efficiency of the network underlying cognitive control in preadolescent children. Neuroscience 199, 166-176. doi: 10.1016/j.neuroscience.2011. 10.009

Voss, M. W., Heo, S., Prakash, R. S., Erickson, K. I., Alves, H., Chaddock, L., et al. (2012). The influence of aerobic fitness on cerebral white matter integrity and cognitive function in older adults: results of a one-year exercise intervention. Hum. Brain Mapp. 34, 2972-2985. doi: 10.1002/hbm. 22119

Vuilleumier, P., Schwartz, S., Duhoux, S., Dolan, R. J., and Driver, J. (2005). Selective attention modulates neural substrates of repetition priming 
and implicit visual memory: suppressions and enhancements revealed by FMRI. J. Cogn. Neurosci. 17, 1245-1260. doi: 10.1162/0898929055 002409

Wager, T. D., and Smith, E. E. (2003). Neuroimaging studies of working memory: a meta-analysis. Cogn. Affect. Behav. Neurosci. 3, 255-274. doi: 10.3758/CABN. 3.4 .255

Wang, C., Zhang, Y., Liu, B., Long, H., Yu, C., and Jiang, T. (2014). Dosage effects of BDNF Val66Met polymorphism on cortical surface area and functional connectivity. J. Neurosci. 34, 2645-2651. doi: 10.1523/JNEUROSCI.3501-13. 2014

Weber, G., Kartodihardjo, W., and Klissouras, V. (1976). Growth and physical training with reference to heredity. J. Appl. Physiol. 40, 211-215.

Winkler, A. M., Kochunov, P., Blangero, J., Almasy, L., Zilles, K., Fox, P. T., et al. (2010). Cortical thickness or grey matter volume? The importance of selecting the phenotype for imaging genetics studies. Neuroimage 53, 1135-1146. doi: 10. 1016/j.neuroimage.2009.12.028

Winkler, A. M., Sabuncu, M. R., Yeo, B. T., Fischl, B., Greve, D. N., Kochunov, P., et al. (2012). Measuring and comparing brain cortical surface area and other areal quantities. Neuroimage 61, 1428-1443. doi: 10.1016/j.neuroimage.2012. 03.026
Wolf, A. M., Hunter, D. J., Colditz, G. A., Manson, J. E., Stampfer, M. J., Corsano, K. A., et al. (1994). Reproducibility and validity of a self-administered physical activity questionnaire. Int. J. Epidemiol. 23, 991-999. doi: 10.1093/ije/23.5.991

Yagi, Y., Coburn, K. L., Estes, K. M., and Arruda, J. E. (1999). Effects of aerobic exercise and gender on visual and auditory P300, reaction time and accuracy. Eur. J. Appl. Physiol. Occup. Physiol. 80, 402-408. doi: 10.1007/s004210050611

Yokum, S., Ng, J., and Stice, E. (2012). Relation of regional gray and white matter volumes to current BMI and future increases in BMI: a prospective MRI study. Int. J. Obes. 36, 656-664. doi: 10.1038/ijo.2011.175

Conflict of Interest Statement: The authors declare that the research was conducted in the absence of any commercial or financial relationships that could be construed as a potential conflict of interest.

Copyright (c) 2016 Herting, Keenan and Nagel. This is an open-access article distributed under the terms of the Creative Commons Attribution License (CC BY). The use, distribution and reproduction in other forums is permitted, provided the original author(s) or licensor are credited and that the original publication in this journal is cited, in accordance with accepted academic practice. No use, distribution or reproduction is permitted which does not comply with these terms. 